\title{
Pattern and degree of radiation exposure during endovascular surgery performed using a mobile C-arm or in a hybrid room
}

\author{
Cheng Quan ${ }^{1}$, Sang Su Lee ${ }^{2}$ \\ ${ }^{1}$ Department of Vascular Surgery, the Second Hospital of Jilin University, Changchun, Jilin, China \\ ${ }^{2}$ Research Institute for Convergence of Biomedical Science and Technology, Division of Vascular and Endovascular Surgery, \\ Department of Surgery, Pusan National University Yangsan Hospital, Yangsan, Korea
}

\begin{abstract}
Purpose: A prospective study was conducted to compare radiation exposure to different parts of an endovascular surgeon's body when using a mobile $\mathrm{C}$-arm with that in a hybrid room.

Methods: Exposure during individual procedures performed on 39 patients with a mobile $\mathrm{C}$-arm and 42 patients in a hybrid room, from July 2016 to December 2016, was evaluated.

Results: The procedures performed, fluoroscopy time, and dose-area product were not significantly different between groups. The dose-area product per second in the hybrid room group appeared greater than in the $\mathrm{C}$-arm group $\left(4.5 \mu \mathrm{Gym}{ }^{2} /\right.$ sec vs. $3.1 \mu \mathrm{Gym}^{2} / \mathrm{sec}$ ). In the C-arm group, the peak skin dose on the right neck (1.77 mSv) and shoulder (1.48 $\mathrm{mSv}$ ) appeared higher than those on their left side $(0.32 \mathrm{mSv}, 0.53 \mathrm{mSv}$, respectively) and the counterparts of the hybrid room group (0.88 mSv, $0.20 \mathrm{mSv}$, respectively).

Conclusion: The peak skin dose in the hybrid room appeared highest for the lower part of the protective apron. The dosearea product per second seemed to be greater in the hybrid room than when using the C-arm. Thus, attention should be focused on protecting the surgeon's upper body when using the $\mathrm{C}$-arm and the lower body when using the hybrid room.

[Ann Surg Treat Res 2019;96(3):131-137]
\end{abstract}

Key Words: Endovascular procedures, Surgeons, Operating rooms, Fluoroscopy, Radiation

\section{INTRODUCTION}

The discovery of X-rays [1] and introduction of X-ray-based techniques in medicine by Wilhelm Roentgen revolutionized the medical field [2]. Although the harmful effects of X-rays are well known and have been the focus of considerable research, the importance of $\mathrm{X}$-rays in the diagnosis and treatment of diseases makes their medical use indispensable.

In recent years, X-ray imaging has also become an important part of interventional therapy. In Europe alone, more than 1 million arteriographic and interventional procedures were performed in 2001 [3]. Interventional procedures guided by fluoroscopy are associated with the highest doses of occupational radiation exposure among medical staff using X-rays [4-7]. Data indicate that a peripheral vascular intervention corresponds to exposure approximately equivalent to 1,500 2,500 , a left ventriculography and coronary angiography to 300 , a coronary stent to 1,000 , and a cardiac radiofrequency ablation
Received February 26, 2018, Revised May 16, 2018,

Accepted June 29, 2018

Corresponding Author: Sang Su Lee

Research Institute for Convergence of Biomedical Science and Technology,

Division of Vascular and Endovascular Surgery, Department of Surgery,

Pusan National University Yangsan Hospital, 20 Geumo-ro, Mulgeum-eup,

Yangsan 50612, Korea

Tel: +82-55-360-2124, Fax: +82-55-360-2154

E-mail: phoenixdr@naver.com

ORCID code: https://orcid.org/0000-0003-0648-976X
Copyright (c) 2019, the Korean Surgical Society

(c) Annals of Surgical Treatment and Research is an Open Access Journal. All articles are distributed under the terms of the Creative Commons Attribution NonCommercial License (http://creativecommons.org/licenses/by-nc/4.0/) which permits unrestricted non-commercial use, distribution, and reproduction in any medium, provided the original work is properly cited. 
to at least 900 chest X-rays [8-12].

Vascular surgery is becoming increasingly endovascular in nature, a procedure aided by the rapid development of X-ray imaging technology and medical devices. In the United States, a 300\% increase has been reported in the number of endovascular treatment procedures performed over the last 10 years for lower extremity vascular disease $[13,14]$. It is reported that about $80 \%$ of abdominal aortic aneurysms can be treated with endovascular therapy, and $40 \%$ to $70 \%$ of all vascular interventions will be performed with an endovascular method in the near future [15].

Despite the increase in the frequency of exposure to X-rays, most practitioners do not have sufficient knowledge about radiation hazards and lack awareness of proper radiation protection. One study suggests that nearly half of junior vascular surgeons do not receive systematic radiation safety training [16]. Without adequate radiation protection equipment and training, long-term occupational exposure to X-rays will increase the risk of serious adverse effects among vascular surgeons.

We compared the exposures of various body parts of the surgeon using a mobile $\mathrm{C}$-arm versus working in a hybrid room.

\section{METHODS}

\section{Subjects}

This study was approved by the appropriate Pusan National University Yangsan Hospital Institutional Review Board (approval number: 05-2017-119). Written informed consent for the procedures was obtained from all patients or their families.

This prospective study included procedures performed on 81 patients from a registered database who underwent endovascular procedures from July 2016 to December 2016. Thirty-nine patients underwent endovascular procedures using a mobile C-arm (OEC9900 Elite, GE, Boston, MA, USA) from July 2016 to September 2016, including 6 endovascular aneurysm repairs (EVARs) and 27 angioplasties; the remaining 6 patients underwent other procedures (angiography, coil embolization, and venography) (Table 1). Forty-two patients underwent endovascular procedures in a hybrid room (Artis Zeego, Siemens, Munich, Germany) from October 2016 to December 2016, including 4 EVARs and 31 angioplasties; 7 patients underwent other procedures (angiography and venography) (Table 1). The X-ray tube was placed below the bed and patient and the image intensifier was above the bed and the patient during procedures.

\section{Radiation exposure dose calculation}

All procedures in the 81 patients were performed by the same surgeon. We attached dosimeters to different regions of the surgeon's body to calculate the differential peak skin dose for those body regions. In the mobile C-arm group, 7 dosimeters were worn, 1 each on the right side of the head, right side of the neck, left side of the neck, right shoulder, left shoulder, chest, and lower part of the protective apron (Fig. 1). For procedures performed in the hybrid room, the surgeon wore the same distribution of another suite of 7 dosimeters. In addition, 2 more dosimeters were added, including 1 on each side of the suspended lead screen (facing the surgeon and patient, respectively). Fluoroscopy time, dose-area product, and peak skin dose were compared between the 2 groups.

\section{Statistical analysis}

Data were analyzed using IBM SPSS Statistics ver. 19.0 (IBM

Table 1. Types of procedures performed, fluoroscopy time, and dose-area product over 3 months in each group

\begin{tabular}{lccc}
\hline \multicolumn{1}{c}{ Variable } & Hybrid $(\mathrm{n}=42)$ & C-arm $(\mathrm{n}=39)$ & P-value \\
\hline Procedure, $\mathrm{n}(\%)$ & & & $0.728^{\mathrm{a})}$ \\
PTA + PTA Hybrid & $31(74)$ & $6(15)$ \\
EVAR & $4(10)$ & $6(15)$ \\
Others & $7(16)$ & 35,481 \\
Fluoroscopy time (sec) & 38,201 & $918 \pm 856.0$ \\
Total & $906 \pm 827.1$ & $838(933)$ \\
Mean \pm SD & $696(929)$ & $44-5,002$ \\
Median (IQR) & $20-4,170$ & \\
Range & $148,350.16$ & $91,608.75$ \\
Dose-area product $\left(\mu \mathrm{Gym}^{2}\right)$ & $3,532 \pm 7,968$ & $2,349 \pm 4,169$ \\
Total & $1,142(1,726)$ & $1,110(1,200)$ \\
Mean \pm SD & $14.2-48,267$ & $144.96-23,020$ \\
Median (IQR) & \\
Range & & $0.795^{\mathrm{b})}$ \\
\hline
\end{tabular}

PTA, percutaneous transluminal angioplasty; EVAR, endovascular aneurysm repair; SD, standard deviation; IQR, interquartile range. ${ }^{\text {a) }}$ Fisher exact test. ${ }^{\text {b) }}$ Student t-test or Wilcoxon rank sum test. 
Co., Armonk, NY, USA). Wilcoxon rank sum test and Student t-test were used for the comparisons. Continuous variables are presented as mean \pm standard deviation. Demographic data were compared using Student t-test or Wilcoxon rank sum test; Fisher exact test was used for categorical variables and the Mann Whitney U-test for continuous variables. $\mathrm{P}<0.05$ was considered to indicate a statistically significant difference.

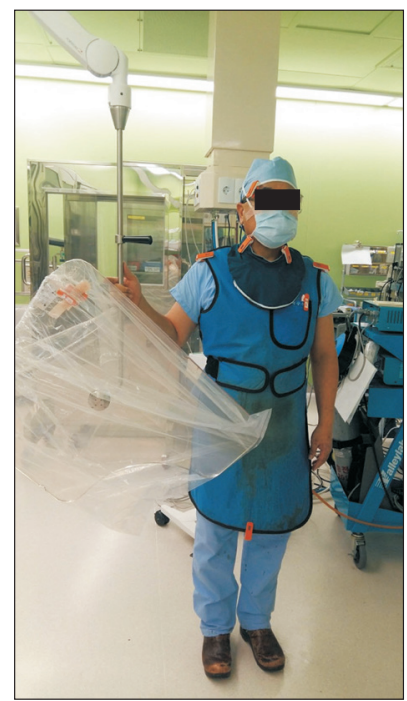

Fig. 1. Bodily locations of the dosimeters. Dosimeters were placed on the right side of the head (1), both sides of the neck (2), both shoulders (1 per shoulder), the chest (1), and the lower part of the protective apron (1).

\section{RESULTS}

The total fluoroscopy time and total dose-area product in the C-arm group and the hybrid room group were 35,481 seconds and 91,608.75 $\mu \mathrm{Gym}^{2}$, respectively, and were 38,201 seconds and $14,8350.16 \mu \mathrm{Gym}^{2}$, respectively (Table 1). The mean fluoroscopy time and mean radiation dose-area product in the C-arm group were 918 seconds and 2,349 $\mu \mathrm{Gym}^{2}$, respectively, and in the hybrid room group, they were 906 seconds and $3,532 \mu \mathrm{Gym}^{2}$, respectively (Table 1 ). There was no statistically significant difference between the 2 groups in terms of the types of procedures performed, fluoroscopy time, and dosearea product (Table 1). We also compared fluoroscopy time and dose-area product between the 2 groups when the same kind of procedure was performed, but no significant difference was observed (Tables 2 and 3). Although there was no significant difference, the dose-area product per second in the hybrid room group appeared greater than that in the C-arm group per unit time $\left(4.5 \mu \mathrm{Gym}^{2} / \mathrm{sec}\right.$ vs. $3.1 \mu \mathrm{Gym}^{2} / \mathrm{sec}$ ) (Table 4). In the C-arm group, the peak skin dose of the right side of the neck (1.77 $\mathrm{mSv})$ and shoulder $(1.48 \mathrm{mSv})$ appeared higher than that of left side (0.32 mSv and $0.53 \mathrm{mSv}$, respectively) and were higher than those of the hybrid room group $(0.88 \mathrm{mSv}, 0.20 \mathrm{mSv}$, respectively). The peak skin dose of the chest $(2.83 \mathrm{mSv})$ and lower part of the protective apron $(2.74 \mathrm{mSv})$ appeared higher than that for any other part of body, including that of the head $(0.77 \mathrm{mSv})$. In the hybrid room group, the peak skin dose of the right side of the neck $(1.77 \mathrm{mSv})$ appeared higher than that of the left side $(0.32 \mathrm{mSv})$; the peak skin dose of the left side of the shoulder $(0.99 \mathrm{mSv})$ appeared higher than that of the right side $(0.20 \mathrm{mSv})$. However, the peak skin dose of the lower part of the

Table 2. Dose-area products resulting from the same procedure in the 2 study groups

\begin{tabular}{cccc}
\hline Procedure & Hybrid $(\mathrm{n}=42)$ & C-arm $(\mathrm{n}=39)$ & P-value \\
PTA & 31 & 27 & $0.230^{\mathrm{a})}$ \\
Number & $2,146 \pm 2,908$ & $1,274 \pm 982$ & $1,010(963)$ \\
Mean \pm SD & $1,374(1,544)$ & $160.36-4,940$ & $0.499^{\text {b) }}$ \\
Median (IQR) & $159.15-14,288$ & 6 & $0.230^{\mathrm{a})}$ \\
Range & 4 & $5,283 \pm 4,641$ & $4,360(3,468)$ \\
EVAR & $19,802 \pm 19,668$ & $1,410-14,020$ & \\
Number & $13,940(12,449)$ & 6 & \\
Mean \pm SD & $3,058.7-48,267$ & $7252 \pm 9199$ \\
Median (IQR) & 7 & $542(591)$ & $144.96-23,020$ \\
Range & $374 \pm 328$ & $313(364)$ & \\
Other & $14.20-962.93$ & & \\
Number & &
\end{tabular}

PTA, percutaneous transluminal angioplasty; EVAR, endovascular aneurysm repair; SD, standard deviation; IQR, interquartile range.

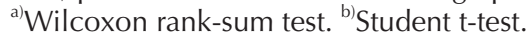


protective apron appeared markedly higher than that for any

Table 3. Fluoroscopy times resulting from the same procedure in the 2 study groups

\begin{tabular}{lccc}
\hline Procedure & Hybrid $(\mathrm{n}=42)$ & C-arm $(\mathrm{n}=39)$ & P-value \\
\hline PTA & & & $0.975^{\mathrm{a})}$ \\
Number & 31 & 27 & \\
Mean \pm SD & $1,003 \pm 873$ & $903 \pm 529$ & \\
Median (IQR) & $705(994)$ & $908(685)$ & \\
Range & $75-4,170$ & $143-2,164$ & \\
EVAR & & & $0.547^{\text {b) }}$ \\
Number & 4 & 6 & \\
Mean \pm SD & $1,127 \pm 748$ & $885 \pm 480$ & \\
Median (IQR) & $920(476)$ & $883(659)$ & \\
Range & $466-2,201$ & $178-1,412$ & \\
Other & & & $0.945^{\text {a) }}$ \\
Number & 7 & 6 & \\
Mean \pm SD & $356 \pm 392$ & $1,015 \pm 1,967$ & \\
Median (IQR) & $101(517)$ & $167(489)$ & \\
Range & $20-1,029$ & $44-5,002$ & \\
&
\end{tabular}

PTA, percutaneous transluminal angioplasty; EVAR, endovascular aneurysm repair; SD, standard deviation; IQR, interquartile range.

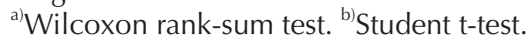

other part of the body, including that of the head $(0.38 \mathrm{mSv})$. The peak skin dose of the lower part of the protective apron in the hybrid room group appeared markedly more than that of the C-arm group ( $8.43 \mathrm{mSv}$ vs. $2.74 \mathrm{mSv}$ ). The peak skin dose of the upper body in the C-arm group appeared higher than that in the hybrid room group; peak skin doses of the right side of the neck and shoulder in the C-arm group appeared markedly higher than those in the hybrid room group $(1.77 \mathrm{mSv}, 1.48$ $\mathrm{mSv}$ vs. $0.88 \mathrm{mSv}, 0.20 \mathrm{mSv}$, respectively). The dosimeter on the surgeon's side of the suspended lead screen recorded $0.18 \mathrm{mSv}$, while that on the patient's side of the screen recorded $1.25 \mathrm{mSv}$ (Table 5).

\section{DISCUSSION}

Endovascular treatment has rapidly replaced open surgery due to the advantages of small incisions or puncture holes, fast recovery, shorter hospital stays, and less pain. However, the clinical advantages of endovascular treatment should be reexamined in light of the exposure of surgeons and patients to X-rays and the concomitant risk of developing cancer [7]. This potentially severe adverse effect may diminish the benefits of minimally invasive treatment.

Table 4. Dose-area products of the 2 study groups per unit time

\begin{tabular}{|c|c|c|c|}
\hline Variable & Hybrid $(n=42)$ & C-arm (n = 39) & P-value \\
\hline Fluoroscopy time (sec) & & & $0.855^{\mathrm{a})}$ \\
\hline Mean $\pm \mathrm{SD}$ & $906 \pm 827.1$ & $918 \pm 856.0$ & \\
\hline Median (IQR) & $696(929)$ & $838(933)$ & \\
\hline Dose-area product $\left(\mu \mathrm{Gym}^{2}\right)$ & & & $0.795^{\mathrm{a})}$ \\
\hline Mean \pm SD & $3,532 \pm 7,968$ & $2,349 \pm 4,169$ & \\
\hline Median (IQR) & $1,142(1,726)$ & $1,110(1,200)$ & \\
\hline Dose-area product per unit time $\left(\mu \mathrm{Gym}{ }^{2} / \mathrm{sec}\right)$ & & & $0.789^{\mathrm{a})}$ \\
\hline Mean \pm SD & $4.5 \pm 6.2$ & $3.1 \pm 3.6$ & \\
\hline Median (IQR) & $1.60(4)$ & $1.59(2)$ & \\
\hline
\end{tabular}

$\mathrm{SD}$, standard deviation; IQR, interquartile range.

${ }^{a)}$ Wilcoxon rank sum test.

Table 5. Peak skin dose recorded by dosimeters placed on different regions of the operator's body

\begin{tabular}{lcc}
\multicolumn{1}{c}{ Position of dosimeters } & C-arm group (mSv) & Hybrid room group (mSv) \\
\hline Right side of the head & 0.77 & 0.38 \\
Right side of the neck & 1.77 & 0.88 \\
Left side of the neck & 0.32 & 0.19 \\
Right shoulder & 1.48 & 0.20 \\
Left shoulder & 0.53 & 0.99 \\
Chest & 2.83 & 2.02 \\
Lower part of the protective apron & 2.74 & 8.43 \\
On the surgeon's side of the suspended lead screen & - & 0.18 \\
On the patient's side of the suspended lead screen & - & 1.25 \\
\end{tabular}


Strategies for reduction or even elimination of the adverse effects of X-ray exposure during diagnostic or therapeutic procedures continue to be important research topics. One approach may be to control the exposure time and amount of X-ray exposure as much as possible for individuals with unavoidable chronic exposure. A wide range of values has been reported for mortality and morbidity caused by exposure to ionizing radiation [17-23]. In addition, a standardized radiation protection policy is currently lacking, which can allow as much as 10 fold higher doses of occupational radiation exposure [24].

In this study, there was no significant difference between the 2 groups regarding types of procedures, fluoroscopy time, and dose-area product. There was also no significant difference between fluoroscopy time and dose-area product between the 2 groups when comparing only values for the same type of procedure. The mean fluoroscopy time for the 2 groups was similar (906 seconds and 918 seconds), but the mean dose-area product of the hybrid room group appeared higher than that of the C-arm group (3,532 $\mu \mathrm{Gym}^{2}$ vs. 2,349 $\mu \mathrm{Gym}^{2}$, respectively). Thus, the dose-area product per unit time seemed to be more than $45 \%$ higher than that in the C-arm group.

In this study, both the mean fluoroscopy time and mean dose-area product in EVAR procedures appeared higher than those for other procedures ( 885 seconds, $5283 \mu \mathrm{Gym}^{2}$ and 1127 seconds, $19802 \mu \mathrm{Gym}^{2}$, respectively) in both groups. This suggests that the surgeon is exposed to more radiation when a more complicated aneurysm condition is being treated because the operation requires a longer fluoroscopy time for installing the stent graft. According to another study [25], during endovascular treatment of an infrarenal aortic aneurysm, the surgeon received a higher effective dose (109 mSv) than that during an interventional procedure for the lower extremity $(47 \mathrm{mSv})$. These dose levels during complex endovascular procedures may approach the safety threshold for skin injury and can lead to an additional $1 \%$ lifetime risk of cancer [26].

The recommendations of the International Commission on Radiological Protection (ICRP) limit exposure to $100 \mathrm{mSv}$ in 5 years ( $20 \mathrm{mSv} / \mathrm{yr}$ with no more than $50 \mathrm{mSv}$ in any 1 year) [27]. In the C-arm group, the region with the highest peak skin dose was the chest, with an average radiation peak skin dose per minute during fluoroscopy of $0.008 \mathrm{mSv} / \mathrm{min}$. In the hybrid room group, the region with the highest peak skin dose was the lower part of the protective apron, with an average radiation peak skin dose per minute during fluoroscopy of $0.013 \mathrm{mSv} /$ min. According to ICRP recommendations, the maximum fluoroscopy time is $4,179.15 \mathrm{~min} / \mathrm{yr}$ when using the C-arm. In the hybrid room, maximum fluoroscopy time is $1,510.51$ $\mathrm{min} / \mathrm{yr}$. However, one report suggested a vascular surgeon can use fluoroscopy for $113,200 \mathrm{~min} / \mathrm{yr}$ before reaching the recommended dose limit, while another recommended up to 154 EVARs and 393 angioplasties yearly $[27,28]$. Thus, the maximum yearly limit of fluoroscopy use herein is much lower than indicated elsewhere. This may relate to our positioning of the dosimeters on the outer surface of, rather than under, the radiation protection equipment.

It seemed the highest peak skin dose by body part in the C-arm group was the chest $(2.83 \mathrm{mSv})$, while in the hybrid room group, it was the lower part of the protective apron $(8.43 \mathrm{mSv})$. Notably, the patterns of radiation exposure differed between the 2 groups. We had hypothesized that the dose-area product in the hybrid room group would be less than that in the C-arm group; however, the results showed no statistical difference. Conversely, the peak skin dose of the lower body in the hybrid room group appeared to be considerably greater than that of the C-arm group. Comparing the patterns of the peak skin doses of the different body regions between groups, the upper body seemed most exposed in the C-arm group and the lower body in the hybrid room group. For example, the doses for the right side of the neck and shoulder in the C-arm group were distinctly higher than those in the hybrid room group (1.77 $\mathrm{mSv}, 1.48 \mathrm{mSv}$ vs. $0.88 \mathrm{mSv}, 0.20 \mathrm{mSv}$, respectively). This may be related to the use of the suspended lead screen in the hybrid room, which reduces the radiation dose to the upper body. We hung the suspended lead screen between the surgeon's upper body and patient (with the suspended lead screen surfaces facing the surgeon and patient, respectively) throughout all procedures performed in the hybrid room in this study. Given the doses recorded on the 2 sides of the lead screen (surgeon's side, $0.18 \mathrm{mSv}$; patient's side, $1.25 \mathrm{mSv}$ ), the effective dose attenuation rate can be estimated as $85.6 \%$. This indicates that, despite the higher total fluoroscopy time and total radiation dose-area product in the hybrid room group, the lead screen can effectively reduce the amount of radiation to which the surgeon is exposed during the procedure. From these observations, we recommend that protection of the upper body, especially the right side, be increased by including a suspended lead screen when using the C-arm. In contrast, protection of the lower body should be the focus when performing the procedure in the hybrid room, perhaps by adding bedside suspended lead screens.

There are many factors, such as the type of endovascular treatment, complexity of the disease, operation time, limitation of the protective equipment, and lack of awareness regarding radiation protection, that have led to a significant increase in radiation exposure among vascular surgeons, especially those lacking experience. If appropriate protection equipment is not used, such practitioners will likely experience adverse effects caused by exposure to X-ray radiation [28]. In addition, vascular surgeons are exploring new methods of guiding modalities for endovascular procedures that do not involve radiation exposure, including ultrasound-guided peripheral artery angioplasty and MRI-guided EVAR $[29,30]$. However, in the absence of 
an appropriate replacement for the use of X-rays, radiation protection measures should continue to be developed, as there is still no measure that can completely eliminate radiation exposure. As is well-known, best personal shielding, rolling and hanging shields, least magnification, collimation, lowest pulse modes, etc., should be routine best practices at present. This study provides some additional advice for enhancing the protection of surgeons, in addition to the factors related to equipment-using skills and equipment-parameter settings. Our data suggest that protection of the upper body, especially the right side of the shoulder and neck when using the C-arm, and protection of the lower body when performing procedures in the hybrid room, should be reinforced to afford the best personal shielding. In particular, a mobile lead shield with holes or combination-type protective equipment could be developed, according to the requirements of common operations, which would not affect the operation itself but would provide maximal protection for the surgeon. Furthermore, improving radiation protection measures and awareness regarding radiation protection should be a long-term goal.
In conclusion, our data suggest that the dose-area product per unit time for exposure during endovascular procedures in the hybrid room seemed to be higher than that when using the C-arm. They also indicate that protection of the upper body, especially the right side of the shoulder and neck, is important when using the C-arm. In contrast, the lower body should be protected when performing the same type of procedure in the hybrid room. A suspended lead screen can effectively reduce exposure of the upper body of the operator. However, protective equipment should be further developed to minimize the radiation exposure of the operators, given that no equipment is currently $100 \%$ effective, and X-ray devices are expected to remain an essential aspect of minimally invasive therapeutic techniques for the foreseeable future.

\section{CONFLICTS OF INTEREST}

No potential conflict of interest relevant to this article was reported.

\section{REFERENCES}

1. Toledo-Pereyra LH. X-rays surgical revolution. J Invest Surg 2009:22:327-32.

2. Nobel lectures in physics 1901-1921. Amsterdam: Elsevier Publishing Company; 1967.

3. Togni M, Balmer F, Pfiffner D, Maier W, Zeiher AM, Meier B, et al. Percutaneous coronary interventions in Europe 19922001. Eur Heart J 2004:25:1208-13.

4. Vano E, Gonzalez L, Guibelalde E, Fernandez JM, Ten JI. Radiation exposure to medical staff in interventional and cardiac radiology. Br J Radiol 1998;71:954-60.

5. Cousins C, Sharp C. Medical interventional procedures-reducing the radiation risks. Clin Radiol 2004:59:468-73.

6. Tsapaki V, Kottou S, Vano E, Parviainen T, Padovani R, Dowling A, et al. Correlation of patient and staff doses in interventional cardiology. Radiat Prot Dosimetry 2005;117:26-9.

7. United Nations Scientific Committee on the Effects of Atomic Radiation. Sources and effects of ionizing radiation. UNSCEAR 2000 Report to the General
Assembly, with Scientific Annexes. New York; United Nations; 2001.

8. Venneri L, Rossi F, Botto N, Andreassi MG, Salcone N, Emad A, et al. Cancer risk from professional exposure in staff working in cardiac catheterization laboratory: insights from the National Research Council's Biological Effects of Ionizing Radiation VII Report. Am Heart J 2009;157:118-24.

9. Neofotistou V, Vano E, Padovani R, Kotre J, Dowling A, Toivonen M, et al. Preliminary reference levels in interventional cardiology. Eur Radiol 2003;13:2259-63.

10. Kocinaj D, Cioppa A, Ambrosini G, Tesorio T, Salemme L, Sorropago G, et al. Radiation dose exposure during cardiac and peripheral arteries catheterisation. Int J Cardiol 2006;113:283-4.

11. Bernardi G, Padovani R, Morocutti G, Vano E, Malisan MR, Rinuncini M, et al. Clinical and technical determinants of the complexity of percutaneous transluminal coronary angioplasty procedures: analysis in relation to radiation exposure para- meters. Catheter Cardiovasc Interv 2000; 51:1-9.

12. Perisinakis $\mathrm{K}$, Theocharopoulos $\mathrm{N}$, Damilakis J, Manios E, Vardas P, Gourtsoyiannis N. Fluoroscopically guided implantation of modern cardiac resynchronization devices: radiation burden to the patient and associated risks. J Am Coll Cardiol 2005:46:2335-9.

13. Goodney PP, Beck AW, Nagle J, Welch HG, Zwolak RM. National trends in lower extremity bypass surgery, endovascular interventions, and major amputations. J Vasc Surg 2009:50:54-60.

14. Giles KA, Pomposelli F, Hamdan A, Wyers M, Jhaveri A, Schermerhorn ML. Decrease in total aneurysm-related deaths in the era of endovascular aneurysm repair. J Vasc Surg 2009:49:543-50.

15. Lipsitz EC, Veith FJ, Ohki T, Heller S, Wain RA, Suggs WD, et al. Does the endovascular repair of aortoiliac aneurysms pose a radiation safety hazard to vascular surgeons? J Vasc Surg 2000;32:704-10.

16. Bordoli SJ, Carsten CG 3rd, Cull DL, 
Johnson BL, Taylor SM. Radiation safety education in vascular surgery training. J Vasc Surg 2014:59:860-4.

17. Efstathopoulos EP, Katritsis DG, Kottou S, Kalivas N, Tzanalaridou E, Giazitzoglou E, et al. Patient and staff radiation dosimetry during cardiac electrophysiology studies and catheter ablation procedures: a comprehensive analysis. Europace 2006;8:4438.

18. Zorzetto M, Bernardi G, Morocutti G, Fontanelli A. Radiation exposure to patients and operators during diagnostic catheterization and coronary angioplasty. Cathet Cardiovasc Diagn 1997;40:348-51.

19. Finci L, Meier B, Steffenino G, Roy P, Rutishauser W. Radiation exposure during diagnostic catheterization and single- and double-vessel percutaneous transluminal coronary angioplasty. Am J Cardiol 1987;60:1401-3.

20. Dash H, Leaman DM. Operator radiation exposure during percutaneous transluminal coronary angioplasty. J Am Coll Cardiol 1984:4:725-8.

21. Bashore TM, Bates ER, Berger PB, Clark
DA, Cusma JT, Dehmer GJ, et al. American College of Cardiology/Society for Cardiac Angiography and Interventions Clinical Expert Consensus Document on cardiac catheterization laboratory standards. A report of the American College of Cardiology Task Force on Clinical Expert Consensus Documents. J Am Coll Cardiol 2001;37:2170-214.

22. Padovani R, Vano E, Trianni A, Bokou C. Bosmans H, Bor D, et al. Reference levels at European level for cardiac interventional procedures. Radiat Prot Dosimetry 2008;129:104-7.

23. Foti C, Padovani R, Trianni A, Bokou C, Christofides S, Corbett RH, et al. Staff dosimetry in interventional cardiology: survey on methods and level of exposure. Radiat Prot Dosimetry 2008;129:100-3.

24. Vano E, Gonzalez L, Fernandez JM, Alfonso $F$, Macaya C. Occupational radiation doses in interventional cardiology: a 15year follow-up. Br J Radiol 2006;79:383-8.

25. Bannazadeh M, Altinel O, Kashyap VS, Sun Z, Clair D, Sarac TP. Patterns of procedure-specific radiation exposure in the endovascular era: impetus for further innovation. J Vasc Surg 2009:49:1520-4.

26. Wrixon AD. New ICRP recommendations. J Radiol Prot 2008;28:161-8.

27. Ho P, Cheng SW, Wu PM, Ting AC, Poon JT, Cheng CK, et al. Ionizing radiation absorption of vascular surgeons during endovascular procedures. J Vasc Surg 2007:46:455-9.

28. Brown KR, Rzucidlo E. Acute and chronic radiation injury. J Vasc Surg 2011:53(1 Suppl):15S-21S.

29. Ascher E, Marks NA, Schutzer RW, Hingorani AP. Duplex-guided balloon angioplasty and stenting for femoropopliteal arterial occlusive disease: an alternative in patients with renal insufficiency. J Vasc Surg 2005;42:1108-13.

30. Raman VK, Karmarkar PV, Guttman MA, Dick AJ, Peters DC, Ozturk C, et al. Realtime magnetic resonance-guided endovascular repair of experimental abdominal aortic aneurysm in swine. J Am Coll Cardiol 2005:45:2069-77. 